\title{
Alginate-based 3D cell culture technique to evaluate the half-maximal inhibitory concentration: an in vitro model of anticancer drug study for anaplastic thyroid carcinoma
}

Hilda Samimi ${ }^{1,2}$, Alireza Naderi Sohi ${ }^{3}$, Shiva Irani ${ }^{2}$, Ehsan Arefian ${ }^{4}$, Mojdeh Mahdiannasser ${ }^{1}$, Parviz Fallah ${ }^{{ }^{*}}$ and Vahid Haghpanah ${ }^{1,6^{*}}$ (D)

\begin{abstract}
Background: Three-dimensional (3D) cell culture methods are identified for simulating the biological microenvironment and demonstrating more similarity to in vivo circumstances. Anaplastic thyroid carcinoma (ATC) is a lethal endocrine malignancy. Despite different treatment approaches, no improvement in the survival rate of the patients has been shown. In this study, we used the 3D in vitro ATC model to investigate the cytotoxic effect of BI-847325 anticancer drug in two-dimensional (2D)- and 3D-cultured cells.
\end{abstract}

Methods: Human ATC cell lines, C643 and SW1736, were cultured in one percentage (w/v) sodium alginate. Spheroids were incubated in medium for one week. The reproducibility of the fabrication of alginate beads was evaluated. Encapsulation of the cells in alginate was examined by DAPI (4,6-diamidino-2-phenylindole) staining. Survival of alginate-encapsulated cells was evaluated by CFSE (5,6-Carboxyfluorescein N-hydroxysuccinimidyl ester) staining. The population doubling times of C643 and SW1736 cell lines cultured in 2D monolayer as well as in 3D system were calculated. The cytotoxic effect of BI-847325 on 2D- and 3D-cultured cell lines was assessed for 24-72 h by MTT [3-(4,5-dimethylthiazolyl-2)-2,5-diphenyltetrazolium bromide] assay. Finally, the 3D culture results were compared with the 2D culture method.

Results: The half-maximal inhibitory concentration $\left(\mathrm{IC}_{50}\right)$ values of $\mathrm{BI}-847325$ were higher in 3D culture compared to $2 \mathrm{D}$ culture. The cytotoxicity data indicated that $3 \mathrm{D}$ in vitro models were more resistant to chemotherapy agents.

Conclusions: The findings of this study are beneficial for developing in vitro ATC 3D models to analyze the efficacy of different chemotherapy drugs and formulations.

Keywords: Anaplastic thyroid carcinoma, Two-dimensional cell culture, Three-dimensional cell culture, Anticancer drug, Half-maximal inhibitory concentration

*Correspondence: parvizfallah@gmail.com; v.haghpanah@gmail.com; vhaghpanah@tums.ac.ir

${ }^{5}$ Department of Laboratory Science, Faculty of Allied Medicine, Alborz University of Medical Sciences (ABZUMS), Taleghani Boulevard, Taleghani Square, Karaj 3155717453, Iran

${ }^{6}$ Personalized Medicine Research Center, Endocrinology and Metabolism Clinical Sciences Institute, Tehran University of Medical Sciences, Tehran, Iran

Full list of author information is available at the end of the article

\section{Introduction}

Thyroid cancer is the most frequent endocrine malignancy with the highest growing incidence rate between the other types of solid tumors in the United States [13]. Anaplastic thyroid carcinoma (ATC), also known as undifferentiated thyroid cancer (UTC), has one of the worst prognoses among other types of thyroid cancer, 
mainly due to its aggressive behavior and resistance to chemotherapy agents [4]. Despite different cancer treatment approaches, there is no improvement in the survival rate of patients [5]. In spite of the basic differences between $2 \mathrm{D}$ conditions and three dimensional (3D) cell environments, merely found in vivo, the majority of in vitro ATC cell culture experiments are performed via monolayer (2D) cells cultured on flask or dish surfaces. Conventional 2D-grown cells have served researchers well for decades, but this culture model is a non-natural system that does not represent the natural microenvironment $[6,7]$.

In general, cancer investigators rely on 2D cell culture in vitro experiments and animal models to understand the complex biological processes of tumor formation, progression and, its treatment $[8,9]$. In recent years, more biologists have started using 3D culture systems, which provide environments more similar to their physiological conditions. 3D cell culture models more closely mimic key factors of natural tumor microenvironment such as molecular concentration gradients and crucial cellular processes such as cell to cell and cell to extracellular matrix (ECM) interactions. These culture systems act as a surrogate for animal models and are less expensive and provide quicker results compared for animal models [10-12]. Therefore, 3D cell culture systems can play an important role in anticancer drug discovery due to the lack of animal models including lower primates or fewer animal models in rare cancers such as ATC, ethical considerations, and advantages greater than 2D cell culture [13].

Scaffold-based 3D cell culture systems are increasingly becoming necessary tools in cancer research [14]. Some hydrogels are polymers that because of their hydrophilic nature, keep high amounts of water following gelation. Hydrogels have high water retention ability due to interconnected microscopic pores, which facilitate easy transport of $\mathrm{O}_{2}$, nutrients, metabolic wastes, growth factors, etc. Therefore, hydrogel scaffolds are used in different pharmaceutical and biomedical fields [6]. Alginate, a natural polymer with the ability to create hydrogel, is known for properties such as its ability to allow diffusion of nutrients and other medium compositions including chemotherapy drugs [6].

Drug discovery and development is still a slow and costly process with little success in clinical trials. At present, more than $50 \%$ of all medicines fail due to lack of effectiveness in Phase II and III clinical trials [12]. Also, just $12 \%$ of drugs that enter clinical trials are ultimately approved to be applied in humans. The importance of in vitro cell culture models is the requirement to more cost-effective advancement of novel chemotherapy drug discovery and time-effective treatment of cancers [15].
The promising methods that are expected to improve drug discovery and development success rate are new preclinical models that better mimic in vivo microenvironmental factors. It is now widely accepted that culturing cells in 3D systems better represents the natural microenvironmental conditions than simple 2D monolayer methods due to more accurate simulation of key tissue factors [16-20]. More efficient drugs are probably developed using more reliable cell culture systems. Therefore, suitable cell culture systems would additionally decrease the requirement for animal trials, particularly for drug toxicity assays [21]. However, the importance of animal models cannot be underestimated in biochemical and physiological studies, cancer research, and drug screening [22].

Recently, scientists have begun studying cancer stem cells (CSCs) in 3D cell culture models and altering culture elements in order to better imitation of in vivo conditions [23, 24]. Culturing CSCs in 2D may reduce their stemness properties, while CSCs cultured in 3D show more resistance against anticancer drugs [23]. Now, there is no doubt that $3 \mathrm{D}$ cell culture systems are biologically further applicable in the field of cancer research because they can provide cellular responses that need more biological communication. At the present, thyroid CSCs have been investigated, especially as the origin of ATC. This subpopulation of cells is responsible for resistance to chemotherapy drugs. Targeted therapy against CSCs has improved ideas in the field of ATC treatment and regenerative chemotherapy drugs [25]. Indeed, MAPK signaling and aurora kinase family are now becoming clear to be involved in thyroid tumorigenesis, particularly in ATC [26]. In the clinic, selective MEK and aurora kinase inhibitors are associated with high levels of response in ATC patients [27]. BI-847325, as a multi-target anticancer drug, selectively and simultaneously inhibits MEK and aurora kinases [28]. Therefore, it can be considered as a candidate for chemotherapy drugs in the treatment of ATC.

In this study, we used the alginate-based $3 \mathrm{D}$ in vitro ATC model as an initiative to investigate the differences between half-maximal inhibitory concentration $\left(\mathrm{IC}_{50}\right)$ of dual MEK/Aurora kinase inhibitor BI-847325 on 2D- and 3D- cultured ATC C643 and SW1736 cell lines.

\section{Material and methods}

\section{D cell culture}

Human ATC cell lines, C643 and SW1736, were acquired from CLS Cell Lines Service GmbH, Germany. Both of the cell lines were cultured in RPMI 1640 medium (Invitrogen, Carlsbad, CA, USA) supplemented with $10 \%$ fetal bovine serum (Invitrogen, Carlsbad, CA, USA), $2 \mathrm{mM}$ glutamine (Sigma-Aldrich, St. Louis, MO, USA), 
100 units of penicillin/ml (Sigma-Aldrich, St. Louis, MO, USA), and $100 \mathrm{mg}$ of streptomycin $/ \mathrm{ml}$ (Sigma-Aldrich, St. Louis, MO, USA). The cells were incubated in $5 \% \mathrm{CO}_{2}$ at $37^{\circ} \mathrm{C}$.

\section{D cell culture}

One percentage (w/v) sodium alginate (Sigma-Aldrich, St. Louis, MO, USA) was prepared in HEPES buffer (Merck Millipore, UK, $20 \mathrm{mM}+\mathrm{NaCl} 155 \mathrm{mM}$, pH 7.4). $\mathrm{CaCl}_{2}$ solution (Merck Millipore, UK, $102 \mathrm{mM}$ ) was prepared in HEPES buffer. C643 and SW1736 cells were resuspended in sodium alginate at $2 \times 10^{5}$ viable cells/ $\mathrm{ml}$. The alginate-cell suspension was extruded through a 22-G needle into the $\mathrm{CaCl}_{2}$ solution. The resultant alginate spheroids remained in the $\mathrm{CaCl}_{2}$ solution for $10 \mathrm{~min}$ at room temperature to induce cross-linking within the alginate. The spheroids were subsequently washed with PBS and then RPMI 1640 with 10\% FBS. Afterward, cells were cultured in alginate spheroids for one week.

\section{Encapsulation and survival of cells in sodium alginate} 3D spheroids of ATC cell lines were prepared using the sodium alginate hydrogel as described above. The obtained spheroids were imaged by a camera (Leica) followed by measuring their size using ImageJ software $(\mathrm{NIH})$. The probability plot for the measured sizes was constructed by Minitab v16 software with a confidence interval of $95 \%$. In the next step, spheroids were washed with PBS and stained separately with DAPI (4',6-diamidino-2-phenylindole) (Sigma-Aldrich, St. Louis, MO, USA) and CFSE (5,6-Carboxyfluorescein N-hydroxysuccinimidyl ester) (Invitrogen, Carlsbad, CA, USA) as described by the manufacturer and imaged with a fluorescence microscope (Nikon TE2000-S).

\section{Calculation of population doubling time}

In the next step, population doubling times of C643 and SW1736 cell lines cultured in 2D monolayer as well as in 3D system were obtained by using the following formula (http://www.doubling-time.com/compute.php) and compared:

$$
\text { Doubling Time }=\frac{\text { Duration } \times \log (2)}{\log (\text { final concentration })-\log (\text { initial concentration })}
$$

\section{Cell viability assay \\ $2 D$ cell culture}

The effect of BI-847325 (Adooq Bioscience) on cell viability was assessed by MTT [3-(4,5-dimethylthiazolyl-2)-2,5-diphenyltetrazolium bromide] assay. The C643 and SW1736 cell lines were seeded in 96-well plates at a concentration of 5000 cells/well. After $24 \mathrm{~h}$ cells were treated with $0.125-8 \mu \mathrm{M}$ doses of BI-847325 for $24-72 \mathrm{~h}$. The viability of the cells was evaluated by the metabolic conversion of the tetrazolium dye to insoluble formazan. MTT $(5 \mathrm{mg} / \mathrm{ml})$ was added to the 96-well plates at $10 \mu \mathrm{l} /$ well, and the plates were then incubated for three hours in $5 \% \mathrm{CO}_{2}$ at $37^{\circ} \mathrm{C}$ incubator. Finally, the formazan crystals were solubilized in $100 \mu \mathrm{l} /$ well DMSO.

\section{$3 D$ cell culture}

The effect of BI-847325 treatment on encapsulated ATC cell lines was also examined by MTT assay. Cells were treated with BI-847325 $(1-64 \mu \mathrm{M})$ for $24 \mathrm{~h}$ as described earlier [29], and currently for $48 \mathrm{~h}$ and $72 \mathrm{~h}$ with the same doses. MTT solution $(5 \mathrm{mg} / \mathrm{ml})$ was added to each well of a 48 -well plate at $10 \mu \mathrm{l} /$ well. Encapsulated cells were incubated for $4 \mathrm{~h}$ in $5 \% \mathrm{CO}_{2}$ at $37^{\circ} \mathrm{C}$ incubator. The medium was removed cautiously with a pipette to avoid the disruption of beads. To dissolve the formazan salt, $500 \mu \mathrm{l}$ of $0.1 \mathrm{M} \mathrm{HCl}$ (Merck Millipore, UK) in 2-propanol (Merck Millipore, UK) was added. Plates were placed in the incubator for $45 \mathrm{~min}$ to allow the formazan to diffuse out of the alginate hydrogel and entirely be dissolved in the solvent [30]. The absorbance of the solution was measured by ELISA reader (BioTek ELx800) at $570 \mathrm{~nm}$. Each experiment was performed in quadruplicate to assess the consistency of results. $\mathrm{IC}_{50}$ values were calculated via the Reed-Muench method [31, 32].

\section{Statistical analysis}

The data show the mean of four independent experiments \pm SD. Statistical analysis of MTT results were performed using One-way ANOVA followed by Tukey's post hoc tests. Statistical significances are expressed as $p<.05\left(^{*}\right) ; p<.01\left(^{* * *}\right) ; p<.001\left(^{(* * *)}\right) ; p<.0001\left(^{(* * * *)}\right) . \mathrm{IC}_{50}$ values were calculated by nonlinear regression using GraphPad Prism v5 software. Statistical comparisons of population doubling times were carried out using the unpaired t-test method in each case $(n=3)$.

\section{Results}

\section{Encapsulation and survival of cells in sodium alginate}

First, to evaluate the reproducibility of the fabrication of alginate spheroids $(n=20)$, their size was measured using ImageJ software (Fig. 1A). According to the probability plot (Fig. 1B), the size of spheroids had a normal distribution $(P$-value $=.352)$ which indicates appropriate reproducibility in spheroids formation. Encapsulation and survival of cell lines are shown in Fig. 2.

\section{Determination of population doubling time}

As shown in Fig. 3, the difference between the population doubling times of cells cultured in 2D and 3D was not statistically significant ( $p$ value $>05$ ) indicating the same growth rate of ATC cell lines in 2D and 3D cultures. 


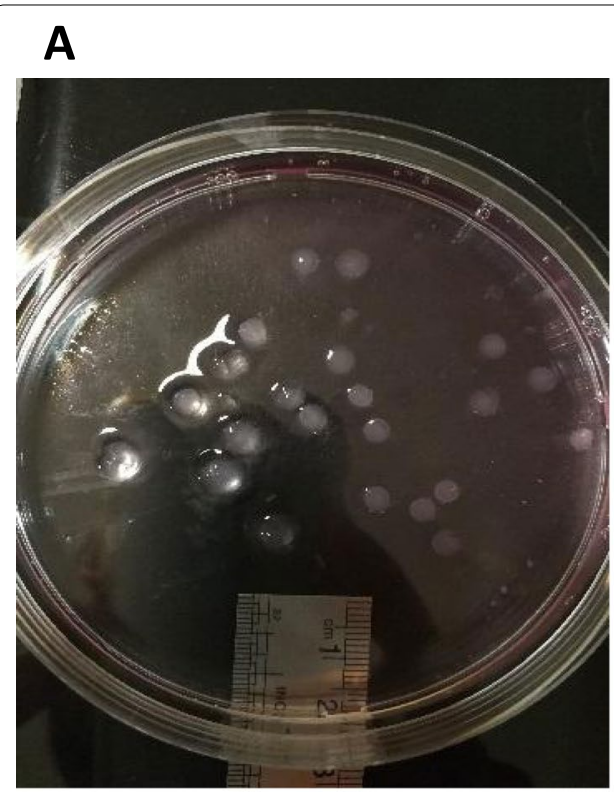

B

Fig. 1 Determination the size of spheroids. (A) A petri dish containing alginate spheroids was imaged to measure the size of spheroids using ImageJ software $(\mathrm{NIH})(n=20)$. (B) Probability plot for the measured sizes. Confidence interval was adjusted to $95 \%$. $P$-value was obtained as .352

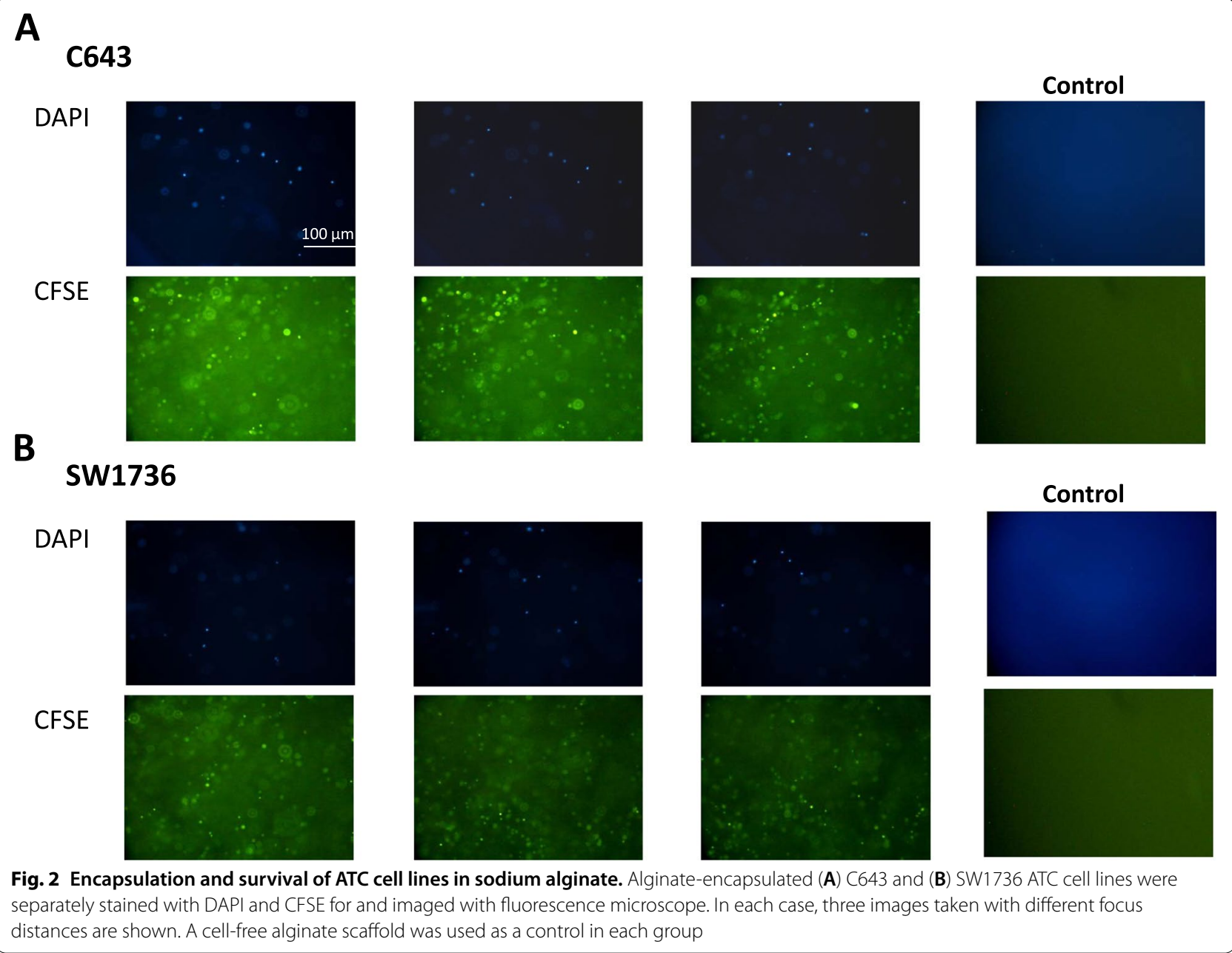




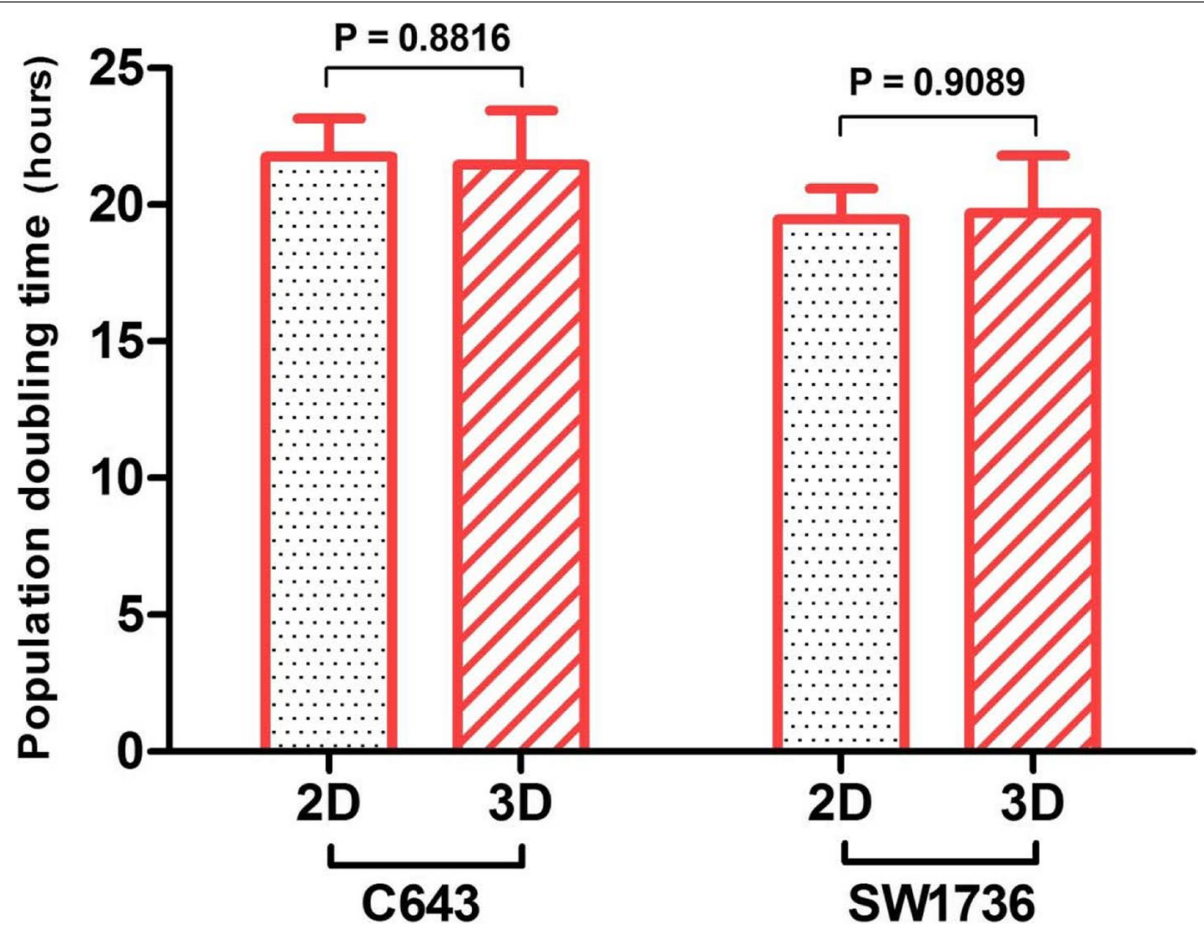

Fig. 3 Population doubling time of C643 and SW1736 cell lines in 2D and 3D culture. $\mathrm{n}=$ three independent experiments. $P$-values were obtained by unpaired t-test method in each case and are represented in graph

\section{Determination of $\mathrm{IC}_{50}$ in the $2 \mathrm{D}$ cell culture system}

Evidence has shown that through carefully selecting thyroid cancer cell lines, an appropriate in vitro model can be developed to analyze the signaling pathways associated with thyroid carcinogenesis [33]. In this study, ATC cell lines with different genetic backgrounds in the MAPK signaling pathway were used, C643 with RAS mutation and SW1736 with $B R A F^{\mathrm{V} 600 \mathrm{E}}$ mutation [33-36]. To evaluate the effect of BI-847325 on the viability of these cell lines, we evaluated the concentration-response and time course of BI-847325 in two selected cell lines. As shown in Fig. 4A, inhibition of cell proliferation occurred in both cell lines in a concentration-dependent manner. The treatment panel of the cell lines with BI-847325 $(0.125-8 \mu \mathrm{M})$ for $24-72 \mathrm{~h}$ prevented proliferation in two cell lines. In both cell lines, $\mathrm{IC}_{50}$ remained constant after $48 \mathrm{~h}$ and $\mathrm{IC}_{50}$ values of BI-847325 on C643 and SW1736 were at $2 \mu \mathrm{M}$ and $4 \mu \mathrm{M}$, respectively (Table 1 ). The $\mathrm{IC}_{50}$ values demonstrated that $\mathrm{C} 643$ cell line was twice as sensitive to BI-847325 compared to the SW1736 cell line.

\section{Determination of $\mathrm{IC}_{50}$ in the 3D cell culture system}

In this study, we examined the effect of dual MEK/ Aurora kinase inhibitor BI-847325 on the viability and proliferation of C643 and SW1736 cell lines that were cultured in 3D alginate spheroids. We found that
BI-847325 significantly inhibited the proliferation of these cell lines. This inhibition occurred in a concentration-dependent manner. The treatment panel of the C643 and SW1736 cell lines with BI-847325 $(1-64 \mu \mathrm{M})$ for $24-72 \mathrm{~h}$ prevented proliferation in the two cell lines (Fig. 4B). In both cell lines the growth-inhibitory effect of BI-847325 remained constant after $48 \mathrm{~h}$ and $\mathrm{IC}_{50}$ values of BI-847325 on C643 and SW1736 were at $15 \mu \mathrm{M}$ and $34 \mu \mathrm{M}$, respectively (Table 1 ).

Interestingly, similar to $2 \mathrm{D}$ cell culture, the $\mathrm{IC}_{50}$ values in the 3D method demonstrated that $\mathrm{C} 643$ cell line is more sensitive towards BI-847325 compared to the SW1736 cell line.

\section{Discussion}

The results of this study are the first report of 3D model for a more accurate assessment of the effect of chemotherapy drugs in ATC. These findings indicate that 3D in vitro models demonstrate more resistance to anticancer drugs. Increased $\mathrm{IC}_{50}$ values in $3 \mathrm{D}$ cell culture system may be associated with multiple mechanisms, including a reduced penetration of chemotherapy agents because of the simulation of key factors of natural tumor microenvironment such as physiological gradients and presence of ECM, enhanced pro-survival signaling pathways such as MAPK pathway due to 

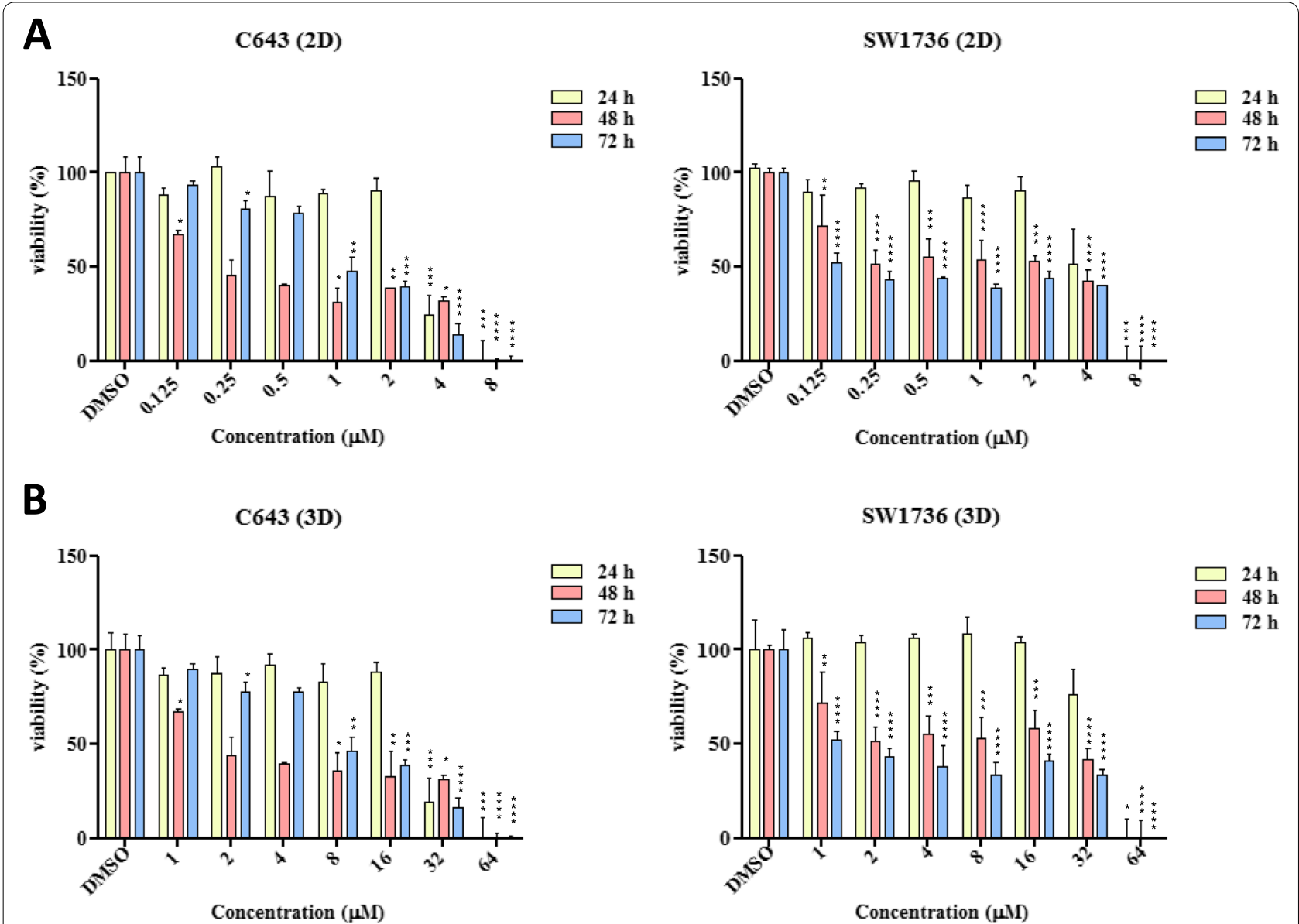

Fig. 4 Inhibitory effects of BI-847325 on viability of ATC cell lines. C643 and SW1736 cell lines were treated with the indicated concentrations of BI-847325 in (A) 2D and (B) 3D cell culture systems for 24-72 h, followed by MTT assay to evaluate cell viability. IC 50 values of BI-847325 for each cell line in two cell culture systems were calculated according to the Reed-Muench methods. The viability of the cells treated by different concentration of drug was normalized to that of untreated ones which were exposed to DMSO with the concentration equal to what existed in drug solutions. This normalization process was performed for each time of assay (i.e. 24,48 , and $72 \mathrm{~h}$ ) separately. For each time point, the viabilities of the cells treated with different concentration of BI-847325 were compared and statistically analyzed via One-way ANOVA and Turkey's post-test method. The significant differences comparing the control (i.e., untreated) cells are represented by star(s) as follows: ${ }^{*} p<.05,{ }^{* *} p<.01,{ }^{* * *} p<.001$, $\left.{ }^{* * * *} p<.0001\right)$

Table 1 Differences between $I_{50}$ values of BI-847325 in 2D and 3D ATC cell culture systems

\begin{tabular}{llll}
\hline Cell lines & Hours & IC $_{50}$ & \\
\hline \multirow{3}{*}{ C643 } & & 2D & 3D \\
& 24 & $3 \mu \mathrm{M}$ & $25 \mu \mathrm{M}$ \\
& 48 & $2 \mu \mathrm{M}$ & $15 \mu \mathrm{M}$ \\
SW1736 & 72 & $2 \mu \mathrm{M}$ & $15 \mu \mathrm{M}$ \\
& 24 & $5 \mu \mathrm{M}$ & $43 \mu \mathrm{M}$ \\
& 48 & $4 \mu \mathrm{M}$ & $34 \mu \mathrm{M}$ \\
& 72 & $4 \mu \mathrm{M}$ & $34 \mu \mathrm{M}$ \\
\hline
\end{tabular}

upregulation of genes involving in anticancer drug resistance [19, 37-41] (Fig. 5).

Furthermore, CSCs cultured in the 2D system may reduce their stemness characteristics, while CSCs cultured in 3D may be more resistant to anticancer drugs $[19,23,42,43]$. Considering the benefits of 3D cell culture systems, mainly in cancer research, we used an in vitro ATC cell culture model by applying a biologically inert alginate hydrogel scaffold for determining the effective dose of dual MEK/Aurora kinase inhibitor BI-847325.

BI-847325 cytotoxicity on ATC C643 and SW1736 cell lines was measured in 2D and 3D cell culture systems. The study has revealed that the concentration ranges used in the 2D cell culture method were not appropriate 


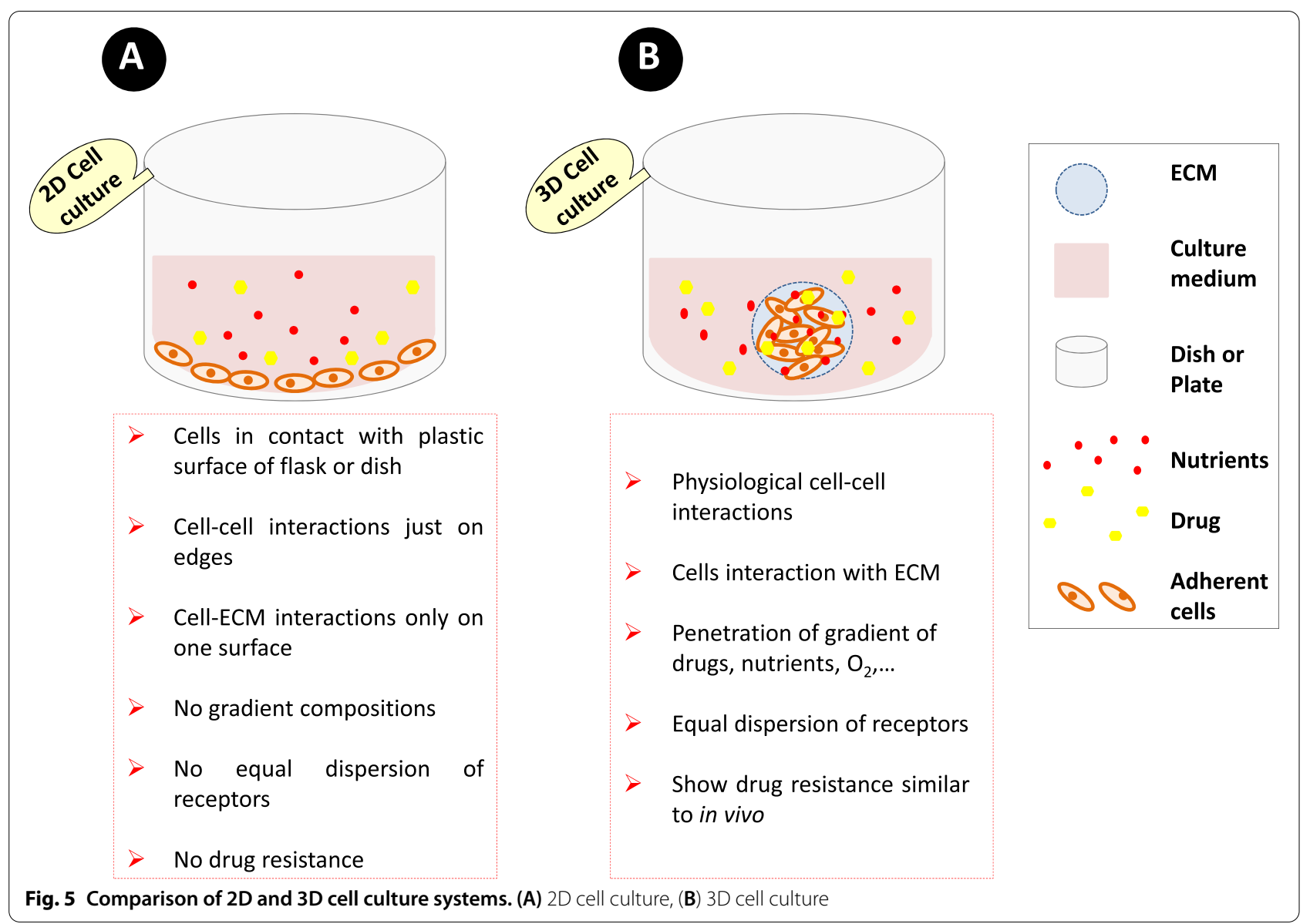

to exhibit significant cytotoxicity in the 3D cell culture system [9]. Based on this evidence, the concentration range of $1-64 \mu \mathrm{M}$ was selected for the determination of the effective dose of BI-847325 anticancer drug in the 3D cell culture method. As anticipated and evidenced in the initial investigation, the $\mathrm{IC}_{50}$ values were significantly higher in the $3 \mathrm{D}$ cell culture system compared to the 2D one for both cell lines (Table 1). The cytotoxicity assay showed that $\mathrm{IC}_{50}$ values of $\mathrm{BI}-847325$ for C643 and SW1736 were at $15 \mu \mathrm{M}$ and $34 \mu \mathrm{M}$ concentrations, respectively. The higher $\mathrm{IC}_{50}$ values in $3 \mathrm{D}$ cell cultures demonstrate the resistance potential gained by cells while growing in the 3D system which simulates the natural physiological conditions. This evidence supports the higher resistance rate of cultured cells in the 3D system to chemotherapy drugs as reported previously [9, 23].

In a similar study, higher viability rates following treatment with Paclitaxel were observed in ovarian cancer cells cultured in 3D compared to 2D cell culture [44]. In another study, comparison of 3D and 2D tumor models in breast cancer was also revealed higher human epidermal growth factor receptor 2 (HER2) activation in the 3D model associated with the less response to Trastuzumab [45]. Therefore, the determination of chemosensitivity in 2D cell culture systems cannot reflect tumor drug sensitivity. These findings indicate that chemotherapy drugs evaluation in the 3D cell culture system may provide useful achievement that is not accessible in conventional 2D investigations.

On the other hand, the subpopulation of malignant cells in the tumor, known as CSCs, is responsible for cancer recurrence and different drug resistance mechanisms [46-48]. We have evaluated the BI-847325 cytotoxicity on ATC C643 and SW1736 cell lines with the CSCs characteristics [49] in two different cell culture models and found that the $\mathrm{IC}_{50}$ values are higher in $3 \mathrm{D}$ cell culture system compared to the 2D cell culture method. Like what observed in $2 \mathrm{D}$ culture, the obtained $\mathrm{IC}_{50}$ in the $3 \mathrm{D}$ culture for SW1736 was higher than that for C643 similar to conventional 2D culture. This observation indicates the resistant nature of this cell line which is probably due to more stemness properties of ATC SW1736 cell line. The elevated $\mathrm{IC}_{50}$ values confirm the Lei and colleagues report about 3D matrix-driven CSCs theory in which 
3D culture of breast cancer cell line, MCF-7, resulted in more tumorigenesis and elevated anticancer drug resistance $[9,23,50]$.

In order to understand the difference between cytotoxic responses of chemotherapeutic drugs in 2D- and 3Dbased culture systems, Godudu et al. examined the uptake efficiency of Doxorubicin inside the alginate-encapsulated lung cancer cell lines [9]. Doxorubicin uptake examination showed that only a low amount of accessible drug $(\sim 10 \%)$ was penetrated into the spheroids. This investigation confirmed the poor permeability of tumors [9]. Because of poor penetration, a high concentration of chemotherapy agents is needed to demonstrate cytotoxicity in tumor cells $[43,51,52]$. This poor penetration of drugs is revealed by several similar models applying 3D cell culture systems based on spheroids [37, 53].

Collectively, 3D cell culture systems such as alginateencapsulated cells more closely mimic the key factors of the natural tumor microenvironment such as molecular concentration gradients and important cellular interactions including cell-cell and cell-matrix communications. However, additional cellular investigations such as xenograft tumors are required to promote the predictive value of 3D cell culture in the response of ATC cells to anticancer drugs in vivo.

\section{Conclusion}

In this study, the cytotoxicity data indicated that 3D in vitro models display more resistance to chemotherapy agents. ATC tumors are unresponsive to the current anticancer drugs. Having to do with 3D in vitro ATC models designed by the current research, it would be feasible to analyze the effect of different anticancer drugs and diverse signaling pathways affected by the chemotherapy agents and formulations. In terms of the future application of the proposed model, this culture system can be modified to support the multicellular 3D cell culture. Moreover, the attachment of different peptides can improve alginate scaffold according to extracellular matrix properties.

\begin{abstract}
Abbreviations
2D: two dimensional; 3D: three dimensional; ATC: anaplastic thyroid carcinoma; CFSE: 5,6-Carboxyfluorescein N-hydroxysuccinimidyl ester; CSC: cancer stem cell; DAPI: 4',6-diamidino-2-phenylindole; ECM: extracellular matrix; ELISA: enzyme-linked immunosorbent assay; HEPES: N-2-hydroxyethylpiperazine-N-ethanesulfonic acid; HER2: human epidermal growth factor receptor $2 ; \mid C_{5}$ : half-maximal inhibitory concentration; MEK: Mitogen-activated protein kinase kinase; MTT: 3-(4,5-dimethylthiazolyl-2)-2,5-diphenyltetrazolium bromide; UTC: undifferentiated thyroid cancer..
\end{abstract}

\section{Acknowledgements}

The authors would like to thanks Dr. Simzar Hosseinzadeh, Ms. Zahra Gohari and Mr. Hamed Samadi for their technical assistance. Also the authors are thankful to Dr. Mahmood Naderi for his helpful suggestions and advice.

\section{Authors' contributions}

V.H. and P.F. designed and supervised the study; H.S. performed experiments and contributed in acquisition of data and manuscript drafting; A.N.S. analyzed data; A.N.S., S.I. and P.F. supervised 3D cell culture in alginate scaffold; E.A., P.F. and M.M. supervised in DAPI and CFSE staining. All authors critically reviewed and approved final version of the manuscript.

\section{Funding}

This research did not receive any specific grant from funding agencies in the public, commercial, or not-for-profit sectors.

\section{Availability of data and materials}

All data generated or analyzed during this study are included in this published article.

\section{Declarations}

Ethics approval and consent to participate

Not applicable.

\section{Consent for publication}

Not applicable.

\section{Competing interests}

The authors declare that they have no conflict of interest.

\section{Author details}

${ }^{1}$ Endocrinology and Metabolism Research Center, Endocrinology and Metabolism Clinical Sciences Institute, Tehran University of Medical Sciences, Tehran, Iran. ${ }^{2}$ Department of Biology, Science and Research Branch, Islamic Azad University, Tehran, Iran. ${ }^{3}$ Department of Nanotechnology and Tissue Engineering, Stem Cell Technology Research Center, Tehran, Iran. ${ }^{4}$ Molecular Virology Lab, Department of Microbiology, School of Biology, College of Science, University of Tehran, Tehran, Iran. ${ }^{5}$ Department of Laboratory Science, Faculty of Allied Medicine, Alborz University of Medical Sciences (ABZUMS), Taleghani Boulevard, Taleghani Square, Karaj 3155717453, Iran. ${ }^{6}$ Personalized Medicine Research Center, Endocrinology and Metabolism Clinical Sciences Institute, Tehran University of Medical Sciences, Tehran, Iran.

Received: 18 July 2021 Accepted: 16 November 2021

Published online: 03 December 2021

\section{References}

1. Sipos J, Mazzaferri E. Thyroid cancer epidemiology and prognostic variables. Clin Oncol. 2010;22(6):395-404.

2. Davies L, Welch HG. Increasing incidence of thyroid cancer in the United States, 1973-2002. Jama. 2006;295(18):2164-7.

3. Jung CK, Little MP, Lubin JH, Brenner AV, Wells SA, Sigurdson AJ, et al. The increase in thyroid cancer incidence during the last four decades is accompanied by a high frequency of BRAF mutations and a sharp increase in RAS mutations. J Clin Endocrinol Metab. 2014;99(2):E276-E85.

4. Wagle N, Grabiner BC, Van Allen EM, Amin-Mansour A, Taylor-Weiner A, Rosenberg $\mathrm{M}$, et al. Response and acquired resistance to everolimus in anaplastic thyroid cancer. N Engl J Med. 2014;371(15):1426-33.

5. Pierie J-PE, Muzikansky A, Gaz RD, Faquin WC, Ott MJ. The effect of surgery and radiotherapy on outcome of anaplastic thyroid carcinoma. Ann Surg Oncol. 2002;9(1):57-64.

6. Lee J, Cuddihy MJ, Kotov NA. Three-dimensional cell culture matrices: state of the art. Tissue Eng Part B Rev. 2008;14(1):61-86.

7. Gevaert M. Engineering $3 \mathrm{D}$ tissue systems to better mimic human biology. Bridge. 2012;42(4):48-55.

8. Szot CS, Buchanan CF, Freeman JW, Rylander MN. 3D in vitro bioengineered tumors based on collagen I hydrogels. Biomaterials. 2011;32(31):7905-12.

9. Godugu C, Patel AR, Desai U, Andey T, Sams A, Singh M. AlgiMatrix ${ }^{\mathrm{TM}}$ based 3D cell culture system as an in-vitro tumor model for anticancer studies. PLoS One. 2013;8(1):e53708. 
10. Weigelt B, Lo AT, Park CC, Gray JW, Bissell MJ. HER2 signaling pathway activation and response of breast cancer cells to HER2-targeting agents is dependent strongly on the 3D microenvironment. Breast Cancer Res Treat. 2010;122(1):35-43.

11. Kenny PA, Lee GY, Myers CA, Neve RM, Semeiks JR, Spellman PT, et al. The morphologies of breast cancer cell lines in three-dimensional assays correlate with their profiles of gene expression. Mol Oncol. 2007;1(1):84-96.

12. Langhans SA. Three-dimensional in vitro cell culture models in drug discovery and drug repositioning. Front Pharmacol. 2018;9:6.

13. Horning JL, Sahoo SK, Vijayaraghavalu S, Dimitrijevic S, Vasir JK, Jain TK, et al. $3-D$ tumor model for in vitro evaluation of anticancer drugs. Mol Pharm. 2008;5(5):849-62.

14. Fischbach C, Kong HJ, Hsiong SX, Evangelista MB, Yuen W, Mooney DJ. Cancer cell angiogenic capability is regulated by 3D culture and integrin engagement. Proc Natl Acad Sci U S A. 2009;106(2):399-404.

15. Paul SM, Mytelka DS, Dunwiddie CT, Persinger CC, Munos BH, Lindborg SR, et al. How to improve R\&D productivity: the pharmaceutical industry's grand challenge. Nat Rev Drug Discov. 2010;9(3):203-14.

16. LaBarbera DV, Reid BG, Yoo BH. The multicellular tumor spheroid model for high-throughput cancer drug discovery. Expert Opin Drug Discov. 2012;7(9):819-30.

17. Griffith $L G$, Swartz MA. Capturing complex 3D tissue physiology in vitro. Nat Rev Mol Cell Biol. 2006;7(3):211-24.

18. Pampaloni F, Reynaud EG, Stelzer EH. The third dimension bridges the gap between cell culture and live tissue. Nat Rev Mol Cell Biol. 2007;8(10):839-45.

19. Oshikata A, Matsushita T, Ueoka R. Enhancement of drug efflux activity via MDR1 protein by spheroid culture of human hepatic cancer cells. J Biosci Bioeng. 2011;111(5):590-3.

20. Seifirad S, Haghpanah V. Inappropriate modeling of chronic and complex disorders: how to reconsider the approach in the context of predictive, preventive and personalized medicine, and translational medicine. EPMA J. 2019;1-15.

21. Prestwich GD. Evaluating drug efficacy and toxicology in three dimensions: using synthetic extracellular matrices in drug discovery. Acc Chem Res. 2007;41(1):139-48

22. Li Z, Zheng W, Wang H, Cheng Y, Fang Y, Wu F, et al. Application of animal models in Cancer research: recent Progress and future prospects. Cancer Manag Res. 2021;13:2455.

23. Chen L, Xiao Z, Meng Y, Zhao Y, Han J, Su G, et al. The enhancement of cancer stem cell properties of MCF-7 cells in 3D collagen scaffolds for modeling of cancer and anti-cancer drugs. Biomaterials. 2012;33(5):1437-44.

24. Smith BH, Gazda LS, Conn BL, Jain K, Asina S, Levine DM, et al. Three-dimensional culture of mouse renal carcinoma cells in agarose macrobeads selects for a subpopulation of cells with cancer stem cell or cancer progenitor properties. Cancer Res. 2011;71(3):716-24.

25. Lin R-Y.Thyroid cancer stem cells. Nat Rev Endocrinol. 2011;7(10):609-16.

26. Marotta V, Sciammarella C, Vitale M, Colao A, Faggiano A. The evolving field of kinase inhibitors in thyroid cancer. Crit Rev Oncol Hematol. 2015;93(1):60-73.

27. Saini S, Tulla K, Maker AV, Burman KD, Prabhakar BS. Therapeutic advances in anaplastic thyroid cancer: a current perspective. Mol Cancer. 2018;17(1):154.

28. Sini P, Gürtler U, Zahn SK, Baumann C, Rudolph D, Baumgartinger R, et al. Pharmacological profile of BI 847325, an orally bioavailable, ATP-competitive inhibitor of MEK and Aurora kinases. Mol Cancer Ther. 2016;15(10):2388-98.

29. Samimi H, Haghpanah V, Irani S, Fallah P, Arefian E, Soleimani M. Determination of ATP-competitive inhibitor drug toxicity in anaplastic thyroid Cancer based on cell characteristics and three-dimensional cell culture. Modares Journal of Biotechnology. 2019;10(3):503-9.

30. Khattak SF, Spatara M, Roberts L, Roberts SC. Application of colorimetric assays to assess viability, growth and metabolism of hydrogel-encapsulated cells. Biotechnol Lett. 2006;28(17):1361-70.

31. Welkos $S, O^{\prime}$ Brien A. Determination of median lethal and infectious doses in animal model systems. Methods Enzymol. 1994;235:29-39.

32. Reed $\sqcup$, Muench $\mathrm{H}$. A simple method of estimating fifty per cent endpoints. Am J Epidemiol. 1938;27(3):493-7.

33. Pilli T, Prasad KV, Jayarama S, Pacini F, Prabhakar BS. Potential utility and limitations of thyroid cancer cell lines as models for studying thyroid cancer. Thyroid. 2009;19(12):1333-42.

34. Samimi H, Fallah P, Sohi AN, Tavakoli R, Naderi M, Soleimani M, et al. Precision medicine approach to anaplastic thyroid cancer: advances in targeted drug therapy based on specific signaling pathways. Acta Med Iran. 2017;55(3):200-8.

35. Meireles AM, Preto A, Rocha AS, Rebocho AP, Máximo V, Pereira-Castro I, et al. Molecular and genotypic characterization of human thyroid follicular cell carcinoma-derived cell lines. Thyroid. 2007;17(8):707-15.

36. Landa I, Pozdeyev N, Korch C, Marlow LA, Smallridge RC, Copland $J A$, et al. Comprehensive genetic characterization of human thyroid cancer cell lines: a validated panel for preclinical studies. Clin Cancer Res. 2019;25(10):3141-51.

37. Kyle AH, Huxham LA, Chiam AS, Sim DH, Minchinton Al. Direct assessment of drug penetration into tissue using a novel application of three-dimensional cell culture. Cancer Res. 2004;64(17):6304-9.

38. Guerra A, Di Crescenzo V, Garzi A, Cinelli M, Carlomagno C, Tonacchera M, et al. Genetic mutations in the treatment of anaplastic thyroid cancer: a systematic review. BMC Surg. 2013;13(Suppl 2):S44.

39. Reddi H, Kumar A, Kulstad R. Anaplastic thyroid cancer an overview of genetic variations and treatment modalities. Adv Genomics Genet. 2015;5:43-52.

40. Are C, Shaha AR. Anaplastic thyroid carcinoma: biology, pathogenesis, prognostic factors, and treatment approaches. Ann Surg Oncol. 2006;13(4):453-64.

41. Kimlin LC, Casagrande G, Virador VM. In vitro three-dimensional (3D) models in cancer research: an update. Mol Carcinog. 2013;52(3):167-82.

42. Thoma CR, Zimmermann M, Agarkova I, Kelm JM, KrekW. 3D cell culture systems modeling tumor growth determinants in cancer target discovery. Adv Drug Deliv Rev. 2014;69:29-41.

43. Kyle AH, Huxham LA, Yeoman DM, Minchinton Al. Limited tissue penetration of taxanes: a mechanism for resistance in solid tumors. Clin Cancer Res. 2007;13(9):2804-10.

44. Loessner D, Stok KS, Lutolf MP, Hutmacher DW, Clements JA, Rizzi SC. Bioengineered 3D platform to explore cell-ECM interactions and drug resistance of epithelial ovarian cancer cells. Biomaterials. 2010;31(32):8494-506.

45. Pickl M, Ries C. Comparison of 3D and 2D tumor models reveals enhanced HER2 activation in 3D associated with an increased response to trastuzumab. Oncogene. 2009;28(3):461-8.

46. Sarkar B, Dosch J, Simeone DM. Cancer stem cells: a new theory regarding a timeless disease. Chem Rev. 2009;109(7):3200-8.

47. Dubrovska A, Elliott J, Salamone RJ, Kim S, Aimone LJ, Walker JR, et al. Combination therapy targeting both tumor-initiating and differentiated cell populations in prostate carcinoma. Clin Cancer Res. 2010;16(23):5692-702.

48. Donnenberg VS, Donnenberg AD. Multiple drug resistance in cancer revisited: the cancer stem cell hypothesis. J Clin Pharmacol. 2005;45(8):872-7.

49. Haghpanah V, Fallah P, Naderi M, Tavakoli R, Soleimani M, Larijani B. Cancer stem-like cell behavior in anaplastic thyroid cancer: a challenging dilemma. Life Sci. 2016;146:34-9.

50. Yang X, Sarvestani SK, Moeinzadeh S, He X, Jabbari E. Three-dimensionalengineered matrix to study cancer stem cells and tumorsphere formation: effect of matrix modulus. Tissue Eng Part A. 2012;19(5-6):669-84.

51. Dhiman HK, Ray AR, Panda AK. Three-dimensional chitosan scaffold-based MCF-7 cell culture for the determination of the cytotoxicity of tamoxifen. Biomaterials. 2005;26(9):979-86.

52. Tannock IF, Lee CM, Tunggal JK, Cowan DS, Egorin MJ. Limited penetration of anticancer drugs through tumor tissue: a potential cause of resistance of solid tumors to chemotherapy. Clin Cancer Res. 2002;8(3):878-84.

53. Ong S-M, Zhao Z, Arooz T, Zhao D, Zhang S, Du T, et al. Engineering a scaffold-free 3D tumor model for in vitro drug penetration studies. Biomaterials. 2010;31(6):1180-90.

\section{Publisher's Note}

Springer Nature remains neutral with regard to jurisdictional claims in published maps and institutional affiliations. 